\title{
BLACK-EYED SUSAN DEFORMITIES
}

ANTHONY I. HRUSKA, P.O. Box 38, Gerald, Saskatchewan. SOA 1 BO

Black-eyed Susans (Rudbeckia hirta L.) which grow in our wild flower garden section have produced some very unusual aberrations this year. These flowers have been growing here for a number of years. The severe mutations (?) were a surprise as none of the plants showed any signs of deformity in previous years. The astonishment came in the fact that so many stems were deformed. All flowers on the affected stems were likewise fused and deformed as can be seen in the illustrations.

The most striking deformities are the four-stem fusions (Fig. 2, 3). Figure 3 shows the various types of deformity and their mode of attachment on the affected stems.

Aberrations and deformities are found in all plants and animals. They generate an interest only in so far as to make you wonder what will follow. Was this a genetic aberration that popped up as a recessive trait, or was it the result of man's use of highly potent chemicals in the area.

HRUSKA, A.J. 1963 Unusual Black-eyed Susan. Blue Jay 21(1):30.

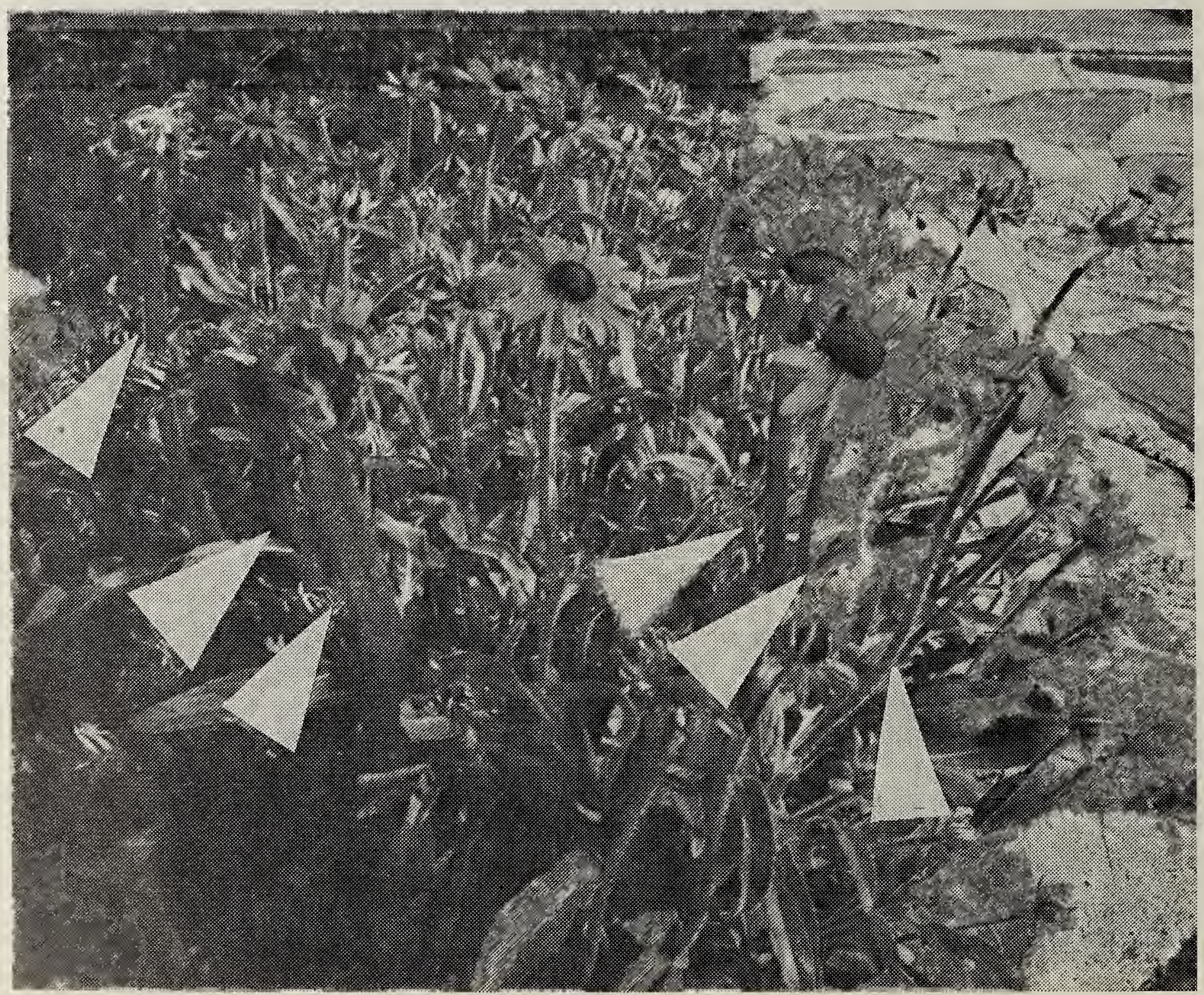

Figure 1 . 


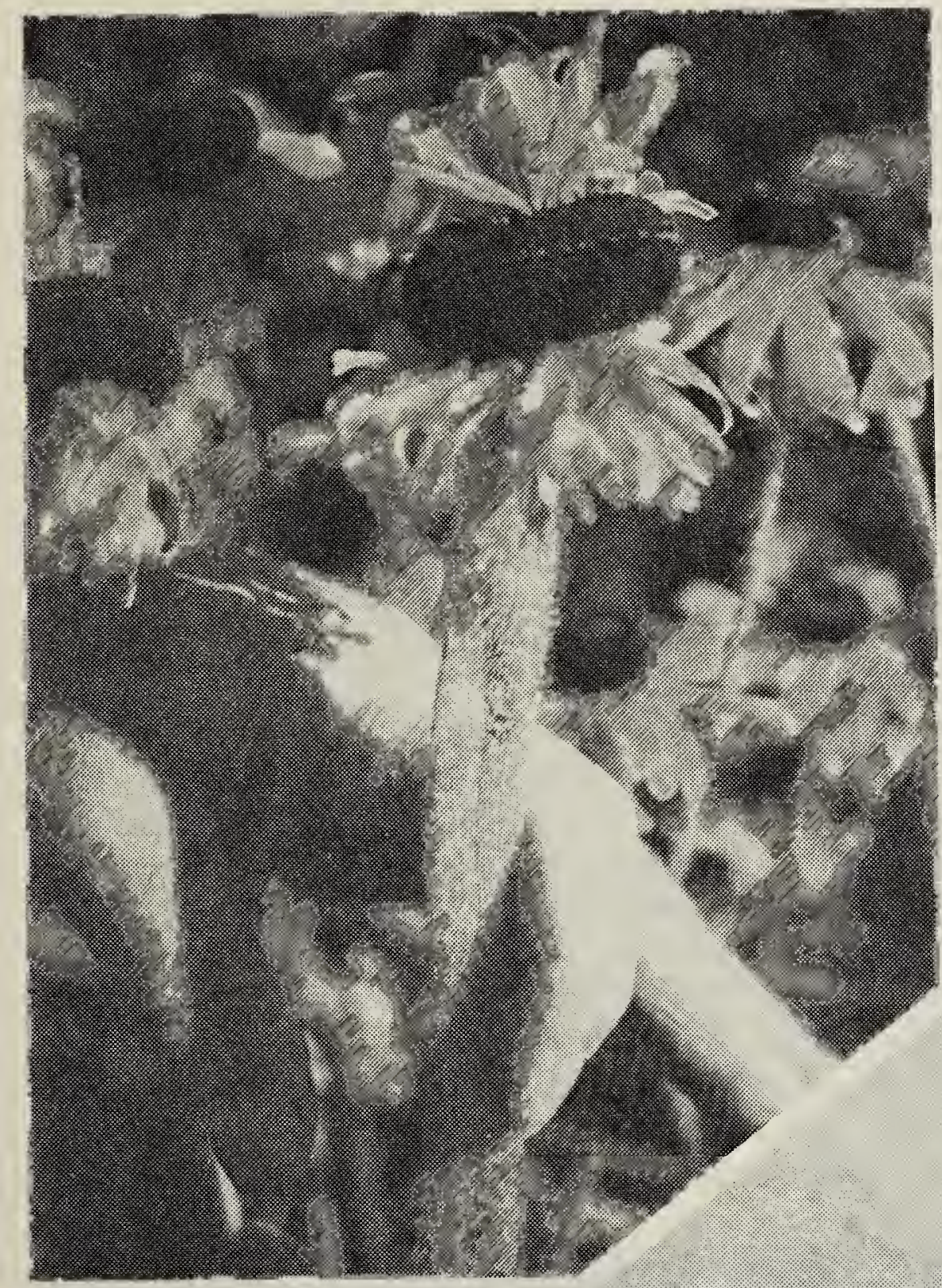

Figure 2.

Figure 3.
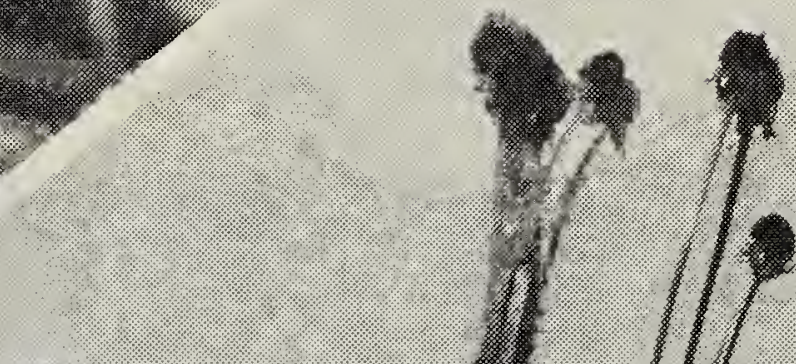